\title{
MARTÍ PERIODISTA, PRECURSOR DEL 98
}

\section{MARTÍ AS JOURNALIST, PRECURSOR OF 98}

\section{Enrique Ríos Vicente}

Profesor Facultad de Ciencias de la Información. Universidad Complutense de Madrid (España) enrios@eucmax.sim.ucm.es

\section{RESUMEN}

José Martí, escritor cubano, fue el periodista mejor informado, formado y completo del siglo XIX, y fue, sobre todo, un gran comunicador. Usaba todos los géneros periodísticos. Martí comenzó en el mundo periodístico por ver en él el medio perfecto para combatir contra la tiranía. Fue considerado un revolucionario por las autoridades españolas. Fue precursor del modernismo y del nuevo estilo periodístico, y uno de los precedentes más significativos y de mayor influencia para la generación y los sucesos acontecidos en 1898. Se le considera el mejor crítico de la vida americana. Para él, el periodismo además de informar debe formar, fundamentalmente.

\section{PALABRAS CLAVE}

Periodista - Escritor - Formar - Revolución

\section{ABSTRACT}

José Martí, a Cuban writer, was the best journalist informed, trained and perfect of the XIX century and was, above all, a great communicator. He used all the journalistic genres. Martí began in the journalistic world to see in it the perfect way to fight against tyranny. It was considered a revolutionary by the Spanish authorities. 
He was a precursor of modernism and the new style of journalism, and one of the most significant precedents and influential for the generation and the events in 1898 . He is considered the best critic of American life. For him, basically, journalism must be well informed.

\section{KEY WORDS}

Journalist - Writer - Training - Revolution

\section{ÍNDICE}

1. Introducción.

2. Primeros pasos periodísticos.

3. Etapa inicial: periodismo político (1871-1875).

4. 2a etapa: México. Inicio de su periodismo total.

5. 3a etapa. El gran periodismo.

6. Última etapa: la revolución y patria (1889-1895)

7. Bibliografía.

\section{Introducción}

"De todos los oficios prefiero el de la imprenta, porque es el que más ha ayudado a la dignidad del hombre" (J osé Martí)

Martí conoce la imprenta y practica como tipógrafo en su fecunda vida periodística. Fue el periodista mejor informado del siglo XIX (Gastón Baquero, 1995: Casa 
América), pero habría que añadir que era el periodista más formado y completo, pues usaba todos los géneros periodísticos y nos ha dejado una obra de algún modo inagotable.

Y continúa siendo todavía la mina a medio volcar, el metal que está a la vez a flor de tierra y metido en vericuetos oscuros del espíritu y del idioma y que es preciso badear muchos años para más sacarlo afuera hasta la última limadura de oro (Mistral, 1938). Nunca la lengua nuestra tuvo mejores tintas, caprichos y bizarrías (Darío, 1929: 236).

Aunque la poetisa chilena se refiere a la obra literaria de Martí, no debe pasarse por alto que el escritor cubano una buena parte de su obra la deja esparcida en multitud de periódicos y revistas.

Por ello se ha dicho que es uno de los más sobresalientes casos del escritor trasvasado casi íntegramente en el periodismo. Salvo sus discursos, sus producciones teatrales y sus versos, todo lo demás.... puede decirse que surgió en el molde periodístico (Lizaso, 1943).

¿Siente Martí de joven la llamada del periodismo? ¿O más bien, el mismo acude al periodismo como el mejor medio de comunicación colectiva? cuando despertó a la vida intelectual, en la casa de su maestro Mendive, vió en el periódico el vehículo para combatir la tiranía (Lizaso, 1943: 11), incluso su iniciación a las ideas krausistas.

Se puede probar, siguiendo las etapas de su vida periodística, que desde adolescente apela al periodismo, pues no en vano, según sus palabras, tiene la prensa periódica altísimas misiones: es la una explicar en la paz, y en la lucha, fortalecer y aconsejar (Martí, 1955: 189). 
En 1862, cuando apenas sobrepasaba los nueve años, -había nacido el 28 de enero de 1853-, cuando ayudaba a su padre que era Capitán Juez en Hanábana (Jagüey Grande), el niño J osé Julián Martí Pérez conoce de cerca los horroes de la esclavitud y jura ante el cadáver de un esclavo ahorcado, lavar con su vida el crimen: Rojo como el desierto / salió el sol al horizonte / y alumbró a un esclavo muerto, / colgado a un seibo del monte / Un niño lo vió: tembló / de pasión por lo que gimen: / $Y$, al pie del muerto, juró / lavar con su vida el crimen! (Martí, 1955: 189).

No es que naciera en ese momento su vocación periodística, pero sí el terror hiere su fina sensibilidad de tal forma que se entregaría totalmente a la redención de "los que gimen" y a la lucha liberadora de su patria oprimida y de las patrias americanas que pudieran serlo en la andadura del tiempo.

En la década de los 60 a los 70, los partidarios del separatismo eran muchos en la Isla y no pocos en España. Entre ellos se contaba Mendive, importante en el círculo intelectual de La Habana, que reunía en su casa a un buen grupo de partidarios de Cuba Libre.

¿Qué se hacía en la casa de Mendive? Allí, comenta Espina, en tertulia de amigos, se hablaba, se discutía, se dibujaban actitudes y se leían con fervor patriótico textos y propagandas revolucionarias. Pocos en número los tertulianos, a nadie cedían en fervor rebelde. Y uno de los más entusiastas era J osé Martí... (Espinsa, 1970: 40).

Este párrafo de Antonio Espinsa le revela gran conocedor del alma de Martí y de los próceres de los países americanos. En cuanto a Martí, refleja la llamada de la propaganda y de la prensa, pues en casa de Mendive se "leían con fervor patriótico textos y propagandas revolucionarias".

1.

\section{Primeros pasos periodísticos}


Sin duda, Martí, poseedor de la palabra, conoce la prensa en casa de Mendive y se da cuenta de que era el mejor medio para desarrollar la vocación a la que era llamado. En 1868 publica sus primeros versos en un periódico local, El Album, de la villa de Guanabacoa; en este caso, dedicados a la segunda esposa de Mendive. Comienza la conquista de la prensa con unos versos, pero al año siguiente, cursando segundo de Bachillerato, insiste en El Diablo Cojuelo, (La Habana, 19 de enero de 1869), que aunque publicado por su "hermano del alma", Fermín Valdés Domínguez (Quesada, 1947:19), lo redacta él sólo casi por completo.

En el publica su primer editorial y primer escrito patriótico, en el que ridiculiza al gobierno despótico de la Isla. Utiliza el periódico como arma política sobre todo a raíz de la libertad temporal de prensa decretada en enero de 1869 por el Capitán General Domingo Dulce.

El 21 del mismo mes publica el soneto "¡10 de octubre!" en el periódico manuscrito El Siboney con motivo del alzamiento de Carlos Manuel de Céspedes. En El Diablo Cojuelo, debido a su carácter satírico, utiliza Martí el comentario humorístico para denunciar los males de la colonia.

Poco más tarde publica otros escritos patrióticos en La Patria Libre (La Habana, 22 de enero, 1869), periódico que dirige y en el que colaboran amigos y compañeros suyos, así como su maestro Rafael María de Mendive. En él publica el poema dramático "Abdala", lleno de alusiones simbólicas que representan a la patria irredenta.

Sin duda, por este tipo de manifestaciones y por su asidua asistencia a la casa de Mendive, el joven Martí era considerado por las autoridades españolas como un ardiente revolucionario. Su maestro Mendive había sido detenido y desterrado con motivo de los sucesos subversivos del Teatro Villanueva de La Habana. 
Primero fue el maestro y poco después el discípulo. Martí da motivo para ello a raíz de una carta que escribieron él y su amigo Valdés Domínguez a un condiscípulo suyo que se había alistado en las tropas españolas y a quien tachan de traidor. Un registro de la policía en la casa de Valdés Domínguez conduce al descubrimiento de la carta y a la detención y procesamiento de ambos. Como Martí se declara totalmente responsible (Quesada) es condenado a seis años de prisión. Su amigo Valdés Domínguez, a seis meses.

\section{Etapa inicial: periodismo político (1871-1875)}

Dante no estuvo en presidio. Si hubiera sentido desplomarse sobre su cerebro las bóvedas oscuras de aquel tormento de la vida, hubiera desistido de pintar su Infierno. Las hubiera copiado, y lo hubiera pintado mejor, escribe Martí en El Presidio Político en Cuba, y esa es la mejor alusión a los espantosos horrores de Las Canteras de San Lázaro a las que fue condenado. El quebranto de su salud fue tan considerable que se teme por su vida y debido a las peticiones y ruegos de sus padres, y sobre todo a la intervención del dueño de las canteras donde realizaban trabajos forzados los presos, José María Sardá Gironella, Martí fue trasladado a la residencia del catalán en la Isla de Pinos, donde se reponde desde octubre a enero. Debido a esas intervenciones se le conmuta la pena por la deportación a España.

El 15 de enero de 1871 embarca para España en el vapor "Guipuzcoa" y arriba a Cádiz a finales del mismo mes. Hacia mediados de febrero Martí se encuentra ya en Madrid. Desde que Martí desembarcara en Cádiz comienza su labor periodística, puesto que ya tenía en la mente lo que diría más tarde de la prensa: tiene la prensa periódica altísimas misiones: es la una explicar en la paz, y en la lucha, fortalecer y aconsejar. 
Martí va a tratar de explicar a los españoles la situación cubana. Nada más llegar a Madrid publica el alegato El Presidio política en Cuba, del que ya publicara anteriormente un avance en un periódico de Sevilla, "La Cuestión Cubana". Como los deportados gozaban en la Península de plena libertad de acción, de residencia y de trabajo, Martí, dice Espina, se adapta pronto a la vida madrileña; frecuenta el Ateneo, los cafés, los teatros, algunos salones de prosapia y los medios obreros, donde puede darse cuenta de las míseras condiciones en que se desenvuelve la vida del pueblo...

El ambiente de la situación era idóneo y atravesaba un buen momento para explicar a todos los españoles no sólo el "estado de las cárceles" sino todo el complejo mundo de la cuestión cubana que interesaba a todos, declarándose unos en favor y otros en contra, pero que apasionaba a la mayoría. Amante y conocedor de la prensa, y sin duda ansiada como el mejor instrumento de comunicación, Martí logra colaboraciones en periódicos como La Discusión y El Jurado Federal, de Madrid; La Soberanía Nacional de Cádiz y La Cuestión Cubana, de Sevilla, entre otros.

Matriculado en Derecho en la Universidad Complutense, Martí comienza una etapa importante de su vida, ya que es el período en que cimienta su formación, Derecho y Filosofía y Letras (Madrid y Zaragoza), y amplia su cultura en distintos campos, algunos de los cuales apenas aún han sido estudiados, como el de su periodismo científico, recientemente descubierto y estudiado por el periodista cubano, Alexis Schlauter, en la revista Bohemia, "El último libro que regaló Martí" y "Lo alemán en la cultura universal de José Martí".

La actividad de Martí en Madrid y Zaragoza es febril. En Madrid muchas noches acude a una tertulia del café de las Columnas, de la Puerta del Sol, donde se reúne con sus compatriotas Calixto García, José Ramón Betancourt, Francisco Ramos, Rafael María de Labra y los españoles Eduardo Benot, Suárez Bravo y Moreno Godínez, entre otros (Espina, 1970: 52). 
Los autores sitúan su primera etapa periodística a su llegada a México en 1875. Pero no se entiende que Martí siendo un niño acuda a un periódico manuscrito escolar para expresar sus ideas en favor de la libertad de Cuba y no lo haga en su período de estudiante en Madrid. Sin duda, su periodismo político comienza en España y se impone investigar las hemerotecas, archivos, etc. de las ciudades donde vive, incluso las de aquellas ciudades que visita, bastantes, sin duda.

La vida española se ve agitada con la abdicación de Amadeo de Saboya el 11 de febrero de 1873 y la proclamación de la República. Tanto Martí como su amigo Valdés Domínguez asisten al acto de proclamación en el Congreso. Dos días más tarde aparece un opúsculo de Martí, "La República española ante la Revolución cubana": Hombre de buena voluntad, saludo a la República que triunfa; la saludo hoy como la maldeciré mañana, cuando una República ahogue a otra República... (Martí, 1873).

Parece que el alegato de Martí cae en el vacío debido al apasionamiento por el estreno del nuevo régimen. Algunas otras voces, tanto en La Habana como en Madrid, se unen a los mensajes políticos del opúsculo de Marftí, quien además, vuelve a insistir con dos artículos: "La Solución" y "Las Reformas" que aparecen en un periódico de Sevilla. El joven cubano sabe perfectamente que algunos ilustres políticos españoles, como el segundo presidente, Pi y Margall, son proclives a solucionar cuanto antes el problema cubano, como lo habían expuesto no pocos en la prensa y el mismo Pi y Margall en la prensa y en el Parlamento.

Martí que conocía perfectamente los problemas cubanos tuvo pluma y palabras para descubrirlos, dice Espina, y dio una conferencia en el Ateneo de Madrid, en la que expuso con toda claridad y vehemencia el problema de Cuba, y no obstante su condición de deportado, también lo explicó en los pasillos del Congreso y en los claustros de la Universidad. 
A comienzos de la primavera de 1873 , el estudiante universitario cubano solicita al Rector de la Universidad Central el traslado de su matrícula a la Universidad Literaria de Zaragoza. La Universidad de Zaragoza (Navarrete, 1953: 7) tuvo el privilegio de contar entre sus alumnos a dos jóvenes destinados a escalar las alturas de la fama. Uno de ellos, nuestro J osé Martí entre los libertadores de América, el otro Santiago Ramón y Cajal entre los sabios de Europa.

En aquella Universidad se graduó Martí en Derecho y en Filosofía y Letras. Martí se integró tan plenamente en la ciudad del Ebro y en la región de Aragón que tuvo unos versos de agradecimiento y recuerdo: Para Aragón en España, /Tengo yo en mi corazón / Un lugar; todo Aragón... (Martí, 1995: 173).

En Zaragoza termina su drama Adúltera, se gradúa de Bachiller (27 de junio), se licencia en Derecho Civil y Canónico (30 de junio) y en Filosofía y Letras (24 de octubre). El Golpe de Estado del general Martínez Campos (Espinsa, 1970: 58) repercute en Zaragoza con trágicos, aunque rápidos, acontecimientos. Se produce resistencia en el pueblo, abundan los tiros y barricadas. El general Burgos, capitán general de la región, procede brutalmente contra todos cuantos ciudadanos no son avalados por párrocos o aristócratas; impone severas sanciones; cañonea barricadas y edificios, causando grandes estragos en San IIdefonso, la Calle Mayor y la Tripería; manda fusilar a cuantos vecinos son cogidos con armas e impone el orden después de tres días de combates callejeros.

No sabemos si Martí y su amigo Valdés permanecen escondidos durante esos breves días de resistencia del pueblo, pero desde luego son testigos una vez más de las barbaridades que se cometieron en la ciudad. Martí conoce perfectamente al pueblo aragonés y le convencen sus virtudes, como demuestra, sin duda, en sus Versos Sencillos: Y si tu alcalde lo aprieta / O lo enoja un rey cazurro, / Calza la manta el baturro / Y muere con su escopeta (Martí, 1995: 173). 
Antonio Espina menciona las palabras de un testigo presencial de los sucesos: "Los Soldados tiraban a matar, no respetando mujeres ni niños". No cita la fuente, pero podían ser palabras de Martí. Dos meses después del golpe de Estado de Martínez Campos, Martí y su amigo Valdés Domínguez salen de Zaragoza hacia Madrid y con documentación falsa cruzan la frontera francesa camino de Francia, donde en breve tiempo, absorbe toda la generosa experiencia del arte y la cultura que en ese instante puede brindarle París (Schultz, 1968: 17).

Su estancia en París es bien aprovechada, ya que a través del poeta Augusto Vacquerie, conocido en Madrid, le presenta a Víctor Hugo. Sin duda, durante esa breve, pero intensa estancia en la capital del Sena, contacta con los círculos literarios, visita museos y galerías de arte, la Universidad de la Sorbona y el Teatro de la Comedia. Durante esa estancia en París es cuando Víctor Hugo le confía la traducción al español de su obra Mes fils.

\section{3. $2^{\mathrm{a}}$ etapa: México. Inicio de su periodismo total}

Apenas llega Martí a México, donde se encuentra con su familia, inicia su periodismo que llamaremos total, ya que sin abandonar el periodismo político, el de ahora será mucho más amplio: científico, cultural, laboral, educativo, o simplemente informativo. Apenas llega a México inicia sus colaboraciones en la Revista Universal, de José Vicente Villada, el 7 de marzo, debido a la introducción de Manuel A. Mercado, quien sería su gran amigo. Su primera colaboración fue un poema dedicado a su hermana Mariana Matilde (Ana) fallecida el 5 de enero. El día 12 de marzo comienza a publicar como folletín en la Revista Universal de México (Quesada, 1947: 91) su traducción de la obra de Víctor Hugo "Mes Fils" ("Mis Hijos"), encargo que había recibido en París del autor francés. 
Participa en los debates sobre materialismo y espiritualismo organizados en el Liceo Hidalgo. Pronto pasa a ocupar en la Revista el cargo de boletinista. Su labor de periodista profesional en la Revista Universal comienza a destacar cuando inicia la redacción de los Boletines que firma con el pseudónimo de Orestes desde primeros de mayo de 1875. En la misma revista entabla una polémica con La Colonia Española y La Iberia, periódicos de españoles residentes en México que atacaban a los insurrectos cubanos e incluso llegaron a mofarse de la bandera de Céspedes, llamándola "banderita": "Banderita no; bandera. Dignísima palabra que cobija a un pueblo..., que tiene héroes activos y mártires errantes..." (Schultz, 1968: 17).

En México, dice Henríquez Ureña (1977: 14-15) se penetra cada vez más de las realidades que él llamó "Nuestra América". México "significaría una de las escuelas donde más aprendió el modo de sentir americano" (Schultz, 1968: 17).

Además, en la capital azteca descubre al indio al que hay que echar a andar (...) para que América pueda marchar adelante; hay que despertar de su espanto a la gran raza dormida (Henríquez, 1977: 14). El periodista Martí político polemista comienza a dar paso al escritor de visión americanista total, continúa el autor antes mencionado. Pero habría que añadir aún más: Martí inicia todos los caminos de su periodismo total: Es el alma del periódico, dice el mexicano Juan de Dios Peza, compañero de Redacción, el que escribe casi siempre el editorial, el Boletín, las Variedades, las Gacetillas, y si hubiera sido necesario, los anuncios, es aquel poeta y orador cubano, lleno de talento, de erudición, de elocuencia, que es una gloria de su patria y que se llama J osé Martí (García del Cueto, 1977: 82).

Las palabras de su compañero de redacción nos descubren a un Martí, periodista pleno, que toca todos los géneros periodísticos y abarca toda la temática de aquel momento mexicano, dando pruebas de un periodismo "ágil, vibrante, reporteril, breve y lleno de colorido, que siempre acompaña de conceptos didácticos, impregnados muchas veces de un lenguaje sentencioso, como verdades 
irrefutables". Al referirse Rubén Darío (1905) al Martí periodista, a sus crónicas y boletines, dice: "Allí aparecía Martí pensador, Martí filósofo, Martí pintor, Martí músico, Martí poeta siempre." Su visión total de periodista no quiere decir que él abandone los temas cubanos, pues aparte de las polémicas, siempre que puede vuelve a insistir en el tema fundamental de su vida: la independencia de Cuba. Por ello, la misma Revista Universal, sale al paso de las críticas contra Martí y el 29 de mayo publica una "Solemne Declaración", en defensa del periodista y de la cuestión cubana.

Con motivo de la guerra civil y del triunfo de Porfirio Díaz la Revista Universal tuvo que cerrar. El 19 de noviembre de 1876 Martí escribe en ella por última vez. Unos días más tarde Porfirio Díaz hace su entrada triunfal en la capital. José Martí aún permanece un poco tiempo en la capital y hasta se atreve a escribir en El Federal un artículo titulado "La Situación" en el que se declara en contra del dictador Porfirio Díaz. En diciembre de ese mismo año sale de México hacia Guatemala.

A principios de 1877 llega Martí a Guatemala. Escribe en la revista de la Universidad temas referentes a la docencia. Pero, de nuevo trata de ejercer el periodismo, ya que concibe la idea y hasta llega a escribir el prospecto de una publicación periódica que debía llamarse Revista Guatemalteca, que debería aparecer en abril de 1878.

Al término de la Guerra de los Diez Años se produce la Paz del Zanjón (1879), por lo que Martí vuelve a Cuba por un breve tiempo durante el que desarrolla una intensa actividad cultural sobre todo a través de sus intervenciones como orador en el Liceo de Guanabacoa. Aunque no ejerce el periodismo, Martí es acusado de nuevo de conspirar contra el Gobierno y es deportado a la Península por orden del General Blanco. En septiembre, día 17 es detenido y el 25 parte hacia su destierro. Desembarca en Santander el 11 de octubre, en cuya cárcel permanece un par de días, ya que fue rescatado por el aval de un diputado de Laredo, que al parecer coincide con él en viaje hacia España. En la ciudad cántabra visita a su madrina y 
después se dirige a Madrid y se entrevista con Cristino Martos el día 19 de noviembre. Antes de terminar el año embarca para Nueva York, donde llega el día 3 de enero de 1880.

\section{2.}

\section{4. $\quad 3^{a}$ etapa: el gran periodismo.}

En la etapa estadounidense Martí desarrollará su más intensa labor periodística a escala continental. A poco de llegar a Nueva York, 3 de enero de 1880, el pintor cubano Guillermo Collazo le relaciona con la revista de arte The Hour (La Hora), en la que Martí comienza sus colaboraciones como crítico de arte.

El día 21 de febrero de 1880 aparece en The Hour su primer artículo en inglés "Raimundo Madrazo". Para la revista The Hour escribe en inglés, aunque muchos de los borradores de sus crónicas estaban redactados en francés, hecho comprensible ya que él mismo anota en sus papeles al iniciar su nuevo trabajo: Yo se un inglés bárbaro, y estas cosas me parecían justas, y me oprimían el corazón. Pero yo tengo confianza en mi energía y en estos ardientes afectos que involuntariamente inspiro... Escribí, temblando, mi revista artística. Yo sabía que escribía español con palabras inglesas... (Martí, 188?).

Martí consigue tal éxito con sus crónicas de arte a pesar de su "inglés bárbaro" que el público llega a comprar la revista The Hour atraído por las magníficas crónicas de Martí: "El hecho es que agradan a los lectores y sus juicios, finos y originales, constituyen una atracción en las páginas de la revista". A través de esta revista, Martí conoce a Charles Anderson Dana, director del periódico The Sun (El Sol), estableciéndose una amistad entre ambos. Dana solicita las colaboraciones de Martí para su periódico de gran tirada. En el periódico de Dana el periodista cubano, además de sus impresiones sobre América en general, va a escribir crónicas sobre la vida norteamericana, que consiguen un gran éxito, ya que Martí escribe lo que le 
parece justo. Cuando Dana leía sus críticas de arte en The Hour sabía que no se equivocaría si solicitaba sus crónicas para su periódico. Su primera colaboración para el Sun versa sobre Bouard y Pécuchet de Flaubert, el 8 de julio de 1880. Recogemos unos párrafos de una crónica "New York y el arte" sobre una exposición de los impresionistas en Nueva York:

“.. acá están todos, naturalistas e impresionistas, padres hijos:

Manet con sus crudezas, Renoir con sus japonismos, Pisarro con sus brumas, Monet con sus desbordamientos, Degas con sus tristezas y sus sombras."

Ninguno de ellos ha vencido todavía. La luz los vence, que es gran vencedora. Ellos la asen por las alas impalpables, la arrinconan brutalmente, la aprietan entre sus brazos, le piden sus favores; pero la enorme coqueta se escapa de sus asaltos y sus ruegos, y sólo quedan de la magnífica batalla sobre los lienzos de los impresionistas esos regueros de color ardiente que parecen la sangre viva que echa por sus heridas la luz rota: ¡Ya es digno del cielo el que intenta escalarlo!

Las palabras de Martí se refieren a la segunda exposición de los impresionistas en Nueva York. Martí escribe diversas crónicas sobre el impresionismo, crónicas que llegan a causar admiración y que contrastan vivamente con las realizadas por los periodistas norteamericanos del momento que no comprenden el impresionismo. Eduardo Degas en sus "Memorias" cuenta la sorpresa que le causaron los artículos y el profundo conocimiento de un periodista y escritor antillano, que había hecho críticas muy certeras de los impresionistas, mientras el resto de los críticos no entendían nada y hasta habían combatido la exposición.

En contra de los consejos de los amigos venezolanos y del propio Dana, Martí decide ir a Venezuela. El propio Dana le ayuda a cambio de que le enviara crónicas para su periódico. En enero de 1881 llega Martí a Caracas y lo primero que hace nada más 
llegar es ir a visitar la estatua de Bolívar. En el mes de junio de 1881 comienza a colaborar en La Opinión Nacional, de Caracas y el día 1 de julio Martí publica la Revista Venezolana. En el segundo y último número, del 15 del mismo mes, publica un artículo elogioso sobre Cecilio Acosta, prócer colombiano que había fallecido. Como Cecilio Acosta había sido opositor a la dictadura de Guzmán Blanco, el artículo de Martí no gusta al presidente, hecho que determina, tras una borrascosa entrevista con el dictador, que el escritor cubano tuviera que abandonar Venezuela y regresar de nuevo a Estados Unidos.

Desde Nueva York comienza a enviar sus crónicas a La Opinión Nacional con el pseudónimo M. de Z., hasta diciembre en que deja de escribir en el periódico de los Aldrey, ya que Martí había recibido una carta en la que se le daban ciertas directrices sobre algunos temas, especialmente sobre los referentes a los que tratasen sobre los Estados Unidos. Martí responde con el silencio más absoluto. Durante ese tiempo también escribe para La Pluma de Bogotá. En 1882, publica Ismaelillo, dedicado a su hijo. Al mismo tiempo escribe gran parte de sus Versos Libres. Precisamente en julio de ese mismo año comienza a redactar las "correspondencias" para La Nación de Buenos Aires. La primera en aparecer, el 13 de septiembre, fue "Muerte de Guiteau". El escritor cubano publica en La Nación de Buenos Aires más de doscientas crónicas. Los Mitre también escriben a Martí que sus artículos eran brillantísimos, pero demasiado negativos. La respuesta de Martí fue que, aparte de dar lo positivo, también daría lo negativo, "pues nuestros pueblos tienen que conocer la realidad". Hay en Martí, dice Portuondo, el mejor crítico de la vida americana y sus Escenas norteamericanas constituyen un brillantísimo panorama de lo que eran los Estados Unidos.

Llega a ser director de la revista La América en 1884. Muchos de sus trabajos en esta revista son importantes colaboraciones sobre temas de enseñanza. La enseñanza en el campo, los maestros ambulantes, las reformas educacionales en los Estados Unidos, etc. En 1885 publica en varias entregas en el periódico El Latino Americano 
la novela Amistad funesta, con el pseudónimo de "Adelaida Ral". Colabora, además, en El Avisador Cubano, de Nueva York. Al año siguiente, el 15 de mayo, escribe su primera correspondencia para El Partido Liberal de México y el 8 de julio inicia también su primera correspondencia para La República de Honduras; y, por otra parte, colabora en el Economista Americano, de Nueva York, en el que escribe extraordinarios planteamientos sobre problemas económicos. También colabora en El Avisador Hispanoamericano, El Porvenir, La Revista Ilustrada y en La J uventud, este último de Gonzalo de Quesada. Durante el año 1887, "más de 20 periódicos de América Latina reproducen sus artículos de La Nación, de Buenos Aires, y El Partido Liberal, de México".

En marzo de 1889, publica en The Evening Post "Vindicación de Cuba", en respuesta a la reproducción que el diario hizo de un artículo "Cuba y los Estados Unidos", del periódico de Filadelfia, The Manufacturer, que trataba de la compra y anexión de Cuba por los Estados Unidos y en el que se menospreciaba a los cubanos. Este año de 1889, por otra causa, iba a representar una de sus más altas cotas periodísticas. Aparecerá la Edad de Oro revista para niños. Fue una forma de periodismo para niños, no sólo desusada en aquella época, sino que además fue la primera manifestación de periodismo de este tipo, al menos dentro del mundo hispánico. La Edad de Oro Publicación mensual de recreo e instrucción dedicada a los niños de América, (julio de 1889), conquistó a los niños de América desde su salida, ya que en la revista iban a encontrar información sobre muchas cosas.

Martí pretendía una educación total para los niños a través del periodismo. Desde la historia, la geografía, el arte, la técnica, las ciencias, la cultura, la literatura, hasta la misma cosmología: "les vamos a decir cómo está hecho el mundo..." La revista, que iba a ser mensual, sólo apareció cuatro veces, durante los meses de julio, agosto, septiembre y octubre de 1889. "Sólo cuatro números llegan a publicarse: ellos forman una obra literaria de valor único, escrita como desde una mentalidad infantil, con toda su fresca belleza; una obra que, en su género, nadie ha logrado igualar en 
español, ni acaso en ningún idioma". Martí sufre una decepción por parte del editor, A. Dacosta Gómez, quien critica a Martí porque su revista nunca hablaba de Dios a los niños y que no daba una orientación religiosa a los niños católicos de habla hispana. Quebró la empresa, porque Martí no aceptó transformar su revista de modo que difundiera esas ideas, y cesó la publicación. Así murió la única revista para niños que se había hecho hasta entonces en nuestra lengua.

\section{5. Última etapa: la revolución y patria (1889-1895)}

Sin embargo, el periodismo de Martí llega a su cumbre con el periódico del Partido Revolucionario Cubano, Patria (14 de marzo de 1895). Este periódico iba a ser su obra maestra, ya que en él va a verte el autor todo lo que entiende que debe ser la prensa ideológica de movimiento libertador. No obstante, en esta su obra maestra, tampoco olvida Martí que el periodismo además de informar debe formar. Por ello, se reafirma, como siempre, su postura respecto a que el periódico debe ser fundamentalmente formador $\mathrm{y}$, desde el primer número manifiesta lo que debe ser el periodismo de Patria:

El periódico ha de estar siempre como los correos antiguos, con el caballo enjaezado, la fusta en la mano y la espuela en el tacón. Al menor accidente, debe saltar sobre la silla, -sacudir la fusta y echar a escape el caballo para salir pronto y para que nadie llegue antes que él. Debe, extractando libros, facilitar su lectura a los pobres de tiempo, - 0 de voluntad o de dinero.

El día 2 de mayo de 1895, a pocos días de su muerte, redacta una carta manifiesto al director del New York Herald, sobre los motivos y principios de la guerra, entregándosela al corresponsal G. E. Bryson. El 14 de mayo, en unión del general Gómez, firma la Proclama a los jefes y oficiales del Ejército Libertador. El día antes de su muerte, día 18, escribe una carta a su amigo Manuel A. Mercado, que deja sin concluir: "Sobre la tabla de pino que en el campamento le había servido de mesa 
quedó inconclusa su última carta a Mercado. Y queda su último trabajo de periodista: un artículo escrito para el Herald de Nueva York, el 2 de mayo de 1895, en el que definía el destino de Cuba: Cuba quiere ser libre para que el hombre realice en ella su ser pleno.

El día 19 de mayo de 1895, después de arengar a las tropas, cae mortalmente herido en la acción de Dos Ríos, el hijo más preclaro de Cuba, el "Apóstol de nuestras libertades", "el mejor hombre de nuestra raza". Quien murió allá en Cuba, era de lo mejor, de lo poco que tenemos nosotros los pobres; era millonario y dadivoso: vaciaba su riqueza a cada instante, y como por la magia del cuento, siempre quedaba rico; hay entre los enormes volúmenes de La Nación, tanto de su metal fino y piedras preciosas, que podría sacarse de allí la mejor y más rica estatua. $Y$, sin duda, fue el mejor periodista del siglo XIX, precursor del modernismo y del nuevo estilo periodístico: Hay tanto que decir, se había expresado en una ocasión, que ha de decirse con el menor número de palabras: eso sí, que cada palabra lleve alas y color. Por ello, Rubén Darío le reprocha cariñosamente al recordar su muerte: Perdona que te guardemos rencor los que te amábamos y admirábamos, por haber ido a exponer y a perder el tesoro de tu talento.

Un trabajo tan corto como éste resultaría demasiado pretencioso, si juzgara haber profundizado en la obra periodística del héroe cubano, pero ni siquiera haber conseguido un esbozo aproximado de su vasto mundo de la comunicación, ya que según Gabriela Mistral tiene aún muchos filones por explotar. Martí comunicador, fue el máximo periodista del siglo XIX y uno de los precedentes más significativos y de mayor influencia a tener en cuenta en las efemérides recapituladotas del 98.

\section{Bibliografía}


DARíO, Rubén. (1905): José Martí en los raros. Barcelona. Maucci ESPINA, Antonio (1970): Martí. Madrid. Compañía Bibliográfica Española.

GARCíA, Mario (1977): "Martí Periodista" en El periodismo de José Martí. La Habana. Orbe.

GARCÍA, J. A. (1977): "El compañero de José Martí" en El periodismo de José Martí. La Habana. Orbe.

HENRÍQUEZ, Camila: (1977): "En torno a Martí, el periodista" en El periodismo de José Martí. La Habana. Orbe.

LIZASO, Félix (1943): Trabajos periodísticos de José Martí. La Habana.

MARINELLO, Juan (1977): Cronología de Martí. La Habana.

MARTí, J osé (1871): El estado de las cárceles en Cuba. Madrid.

MARTí, José (1873): La República Española ante la Revolución Cubana. La Habana.

MARTí, J osé (1886): "Nueva York y el arte" en La Nación. Buenos Aires.

MARTí, José (1889): La Edad de Oro. Nueva York.

MARTí, José (1892): Patria. Nueva York.

MARTí, J osé (1939-1959): Obras Completas. La Habana.

MARTí, José (1955): Versos Sencillos. Madrid. Alianza Editorial.

NAVARRETE, A. (1953): Martí, estudiante universitario. La Habana.

QUESADA, Gonzalo (1947): Guía para las obras completas de Martí. La Habana. Trópico.

QUESADA, Gonzalo (1977): Así fue Martí. La Habana. Gente Nueva.

RIPOLL, Carlos (1971): Archivo José Martí. Repertorio crítico. Nueva York.

SCHLATER, Alexis (1993): "El último libro que regaló J osé Martí" en Bohemia. 14 de mayo. La Habana.

SCHLATER, Alexis (1994): "Lo alemán en la cultura universal de Martí" en Bohemia, 16 de septiembre. La Habana.

SCHULTZ, Fryda (1968): Genio y figura de José Martí. Editorial Universitaria. Buenos Aires. 